\title{
LEITURA: UM RETRATO DAS PRÁTICAS EM SALA DE AULA
}

\author{
Márcia Regina Melcior Landim ${ }^{1}$ \\ Onici Claro Flôres ${ }^{2}$
}

\begin{abstract}
Resumo: $\mathrm{O}$ presente artigo busca problematizar o trabalho com leitura nas diferentes áreas do conhecimento, confrontando a fala do professor em relaçáo a sua prática com as percepçóes do aluno sobre o papel desta para a sua aprendizagem. O trabalho é resultado de uma pesquisa quantitativa com professores de todas as áreas do conhecimento de uma escola pública e uma particular do município de Venâncio Aires, e com alunos do $8^{\circ}$ ano de ambas as escolas. Os dados apurados permitem uma reflexão sobre as prováveis causas do insucesso dos alunos nas avaliaçóes de leitura e sinalizam a necessidade de mudanças urgentes na prática docente.
\end{abstract}

Palavras-chave: Leitura. Ensino. Aprendizagem.

\section{READING: A PORTRAIT OF PRACTICES IN A CLASSROOM}

\begin{abstract}
This article seeks to problematize the work with reading in the different areas of knowledge, confronting the teacher's speech in relation to its practice with the perceptions of the student about the role of this one to his learning. The work is the result of a quantitative research with teachers from all areas of knowledge of a public school and a private school in the city of Venâncio Aires, and with 8 th grade students from both schools. The obtained data allow a reflection on the probable causes of the failure of the students in the evaluations of reading and signal the necessity of urgent changes in the teaching practice.
\end{abstract}

Keywords: Reading. Teaching. Learning.

\section{Introduçáo}

No topo das competências e habilidades a serem desenvolvidas e alcançadas pela disciplina de Língua Portuguesa está o domínio da leitura e da compreensão leitora. Então, como explicar o fato de um aluno que fica 8/9 anos numa sala de aula não alcançar tal competência? Como a escola trabalha a leitura? Qual a ação

1 Doutoranda - Programa de Pós-Graduação em Letras - UNISC

2 Professora do Programa de Pós-Graduação em Letras - UNISC 
do professor e da escola para estimular a leitura e torná-la uma prática constante na vida do estudante?

De acordo com dados do Pisa (Programa Internacional de Avaliação de Alunos), em 2015, o desempenho dos estudantes brasileiros em leitura piorou em relação a 2012. O país somou 407 pontos em leitura, três a menos que a sua pontuação na última avaliação e 86 pontos abaixo da média dos países da OCDE (Organização para Cooperação e Desenvolvimento Econômico), ficando com a $59^{\mathrm{a}}$ posição no ranking de leitura. Ainda segundo os dados desta avaliação, "quase metade $(49,2 \%)$ dos alunos brasileiros não alcançou o nível 2 de desempenho na avaliação que tem o nível 6 como teto", o que significa que eles não são capazes de deduzir informações do texto, de estabelecer relações entre diferentes partes do texto e não conseguem compreender nuanças mais sutis de linguagem. Daí a motivação do nosso trabalho, que buscou refletir sobre as práticas de leitura adotadas pela escola, levantar informações com professores sobre como trabalham a leitura e qual o papel para o desenvolvimento do seu trabalho e, também, analisar o modo como os alunos participantes percebem a leitura e como reagem a ela nas atividades propostas pela escola. Para tal, realizou-se um questionário com 15 professores de todas as áreas do conhecimento de uma escola pública e uma particular e com alunos do $8^{\circ}$ ano de ambas as escolas. Os dados coletados serão detalhados na seção seguinte, seguidos de uma análise comentada.

\section{A leitura na sala de aula}

A leitura tem se configurado nos últimos anos como o grande desafio de professores de todas as áreas do conhecimento, nos diferentes níveis de ensino. Em qualquer roda de conversa entre professores, sempre surge a dificuldade de fazer os alunos ler ou de entender aquilo que leram. Normalmente, o insucesso é atribuído à preguiça do estudante, à questão social e/ou familiar, ao número de alunos na turma; em raras exceções se questionam as estratégias utilizadas para trabalhar a leitura em sala de aula. A leitura que se faz disso é que os professores pressupõem que os alunos que já se apropriaram da leitura, ou seja, já conseguem decodificar o código escrito, já sabem ler e não precisam de intervenções direcionadas para aprender novas técnicas e estratégias de leitura. E aí reside o problema: os alunos que chegam nos anos finais, por exemplo, não conseguem resolver questões que exigem interpretação, que exigem uma resposta considerando informações de várias partes do texto, não conseguem preencher as lacunas deixadas pelo texto (as mais diversas) nem lidar com textos com configuração pouco familiar (textos não contínuos, gráficos e tabelas, formulários), pois a escola considera que a leitura é uma habilidade que, uma vez aprendida na etapa de alfabetização, pode ser aplicada sem problemas a múltiplos textos. No entanto, muitas pesquisas mostram que isso não é verdade. É necessário o planejamento de estratégias específicas que ensinem os alunos a lidar com as tarefas de leitura dentro de cada disciplina.

Lerner (2002) suscita uma série de questionamentos sobre o modo como a leitura e a escrita são ensinadas na escola. Para a autora, o ensino dessas duas 
habilidades ainda tem uma finalidade puramente didática. A escola, ao ensinar a ler e a escrever, foca na transmissão de saberes e comportamentos culturais, distanciando o ensino da função social que pressupõe ler para se comunicar com o mundo, ler para encontrar informação que leve à compreensão de algum aspecto do mundo, ler para tornar-se crítico e assumir posicionamento diante dos fatos.

Para Flores e Pereira (2000, p.11), a leitura "não se reduz a limitadas concepções da realidade cotidiana". É a leitura que "dá curso a um modo de pensar e sentir tudo o que nos cerca, sem que isso signifique, mera representação". A leitura "faz a expressividade do mundo surgir como linguagem" e também se transforma em escrita. Quem lê, escreve melhor, pois representa na forma escrita os esquemas mentais construídos durante a leitura; a leitura expande três grandes sistemas de conhecimento de que dispomos: o linguístico, o enciclopédico e o interacional. $\mathrm{O}$ primeiro compreende o conhecimento gramatical e lexical, o segundo é aquilo que se encontra na memória de cada indivíduo e o terceiro tem a ver com as formas de interação através da linguagem. Portanto, na escola, a leitura deve ser uma tarefa de todas as disciplinas.

Solé (1998) defende essa ideia e complementa que o ensino deve ser estendido ao longo da escolaridade. Para a autora, o ensino da leitura "não deve ser questão de um curso ou um professor, mas questão de escola, de projeto curricular e de todas as matérias" (SOLÉ, 1998, p.18-19), porque a leitura é mais do que um meio de adquirir informação; a leitura desenvolve a criticidade e a autonomia de pensamento, possibilita uma visão mais ampla dos fatos. Mas, para que o leitor atinja esse patamar, é necessária uma intervenção de maneira específica e direcionada. Daí a necessidade de o professor pensar em estratégias de leitura. Para Solé (1998), as estratégias permitem ao estudante interpretar e compreender de forma autônoma os textos lidos; elas também ajudam a utilizar o conhecimento prévio, a realizar inferências para interpretar o texto, ou a identificar aquilo que não se entende.

Sobre o ensino de estratégias de compreensão leitora, Morais (2013, p.120) fala que um dos objetivos mais importantes é "permitir ao aluno a autorregulação, o que implica lhe dar meios para gerir e controlar sua progressão na leitura do texto", E nesse sentido, as estratégias utilizadas pelo professor devem orientar o aluno leitor a prestar atenção nas pistas que o texto apresenta, a identificar o objetivo da leitura, a relacionar a informação apresentada com o conhecimento que se tem sobre o assunto. Muitas das estratégias de compreensão, "dependem da prática e do grau de familiaridade com o domínio de conhecimento do texto" (MORAIS, 2013), por isso, textos atuais e de temáticas que despertem o interesse dos leitores, considerando a faixa etária e preferências da turma, são ótimas estratégias para desenvolver o hábito e, por conseguinte, o gosto pela leitura.

Nesse sentido, o professor tem papel fundamental na formação do leitor; em muitos casos, ele é a única figura que representa o leitor. E ele precisa mostrar o gosto que tem pela leitura, comentando os livros preferidos, recomendando títulos e autores, levando um exemplar para si mesmo quando for com a turma 
à biblioteca. Os estudantes precisam encontrar bons modelos de leitor na escola, especialmente aqueles cuja família não é formada de leitores assíduos.

De outra parte, a leitura não deve apenas ser trabalhada e cobrada nas aulas de Língua Portuguesa; todas as áreas têm esse compromisso. Em diversas situações, nas mais variadas áreas do conhecimento, os alunos devem ser levados a debater as ideias apresentadas pelo texto, a exercitar a interpretação, a posicionar-se diante do que é apresentado pela leitura. A formação plena da cidadania depende da autonomia de pensamento possibilitada pela leitura.

Partindo deste raciocínio, nos propomos a investigar como a leitura tem sido trabalhada nas salas de aula. Para tal, elaboramos um pequeno questionário que foi aplicado a 15 professores, 6 de escola particular e 9 de escola pública. Também responderam ao nosso instrumento de pesquisa, 51 alunos, 25 de escola particular e 26 de escola pública. Em nenhum momento tivemos a intenção de comparar dados entre os tipos de escola ou de ensino, buscando dizer qual trabalha mais e melhor a leitura, tanto que as informações coletadas foram agrupadas e contabilizaram um único percentual. Nosso propósito em escolher uma escola particular e uma pública foi o de abarcar a realidade existente e não o de considerar os resultados em relação a esta ou aquela escola. Buscamos fazer um recorte da realidade do trabalho com leitura desenvolvido em sala de aula.

Consideramos satisfatória a participação dos professores, pois, dos 22 questionários entregues, 15 foram respondidos e devolvidos. Ressaltamos que questionários foram deixados na escola com a supervisão para serem respondidos pelos professores durante reunião pedagógica e os professores foram convidados a contribuir, não existindo caráter de obrigatoriedade na solicitação. Já em relação aos alunos, tivemos o cuidado de encontrar duas turmas com o mesmo número de alunos, sendo que apenas um não respondeu, pois estava ausente no dia da realização do trabalho. A respeito da tipologia das questões feitas, podemos dizer que, basicamente, foram questões de múltipla escolha, cabendo aos professores e alunos, marcar as suas opções.

Apresentamos, a seguir, as análises resultantes do trabalho realizado. Entretanto, é válido mencionar que aqui se encontram analisados os dados de apenas duas salas de aula e de uma parte muito pequena de professores que trabalham nos sistemas público e particular de ensino do RS. Não queremos, em hipótese alguma, generalizar os resultados obtidos pelo trabalho, apenas pensar um pouco sobre o que esses dados querem nos dizer.

Buscamos confrontar as respostas dos professores com as respostas dos alunos, fazendo um contraponto entre discurso e prática, na tentativa de compreender as nuanças deste complexo ato que envolve o ensinar e o aprender. A primeira questão feita aos professores investigava se os alunos liam em suas aulas e aos alunos perguntamos se a leitura é exigida em todas as disciplinas.

$\mathrm{Na}$ Figura 1, apresentamos as respostas dos professores, as quais nos surpreenderam bastante. Quase metade deles respondeu que os alunos não leem. Essa informação nos deixou muito intrigados: por que os alunos não leem? Será 
que os professores não cobram a leitura? Não existem momentos de leitura em sala de aula? São os professores que leem quando resolvem trabalhar com um texto? Ou são os mesmos alunos que sempre se dispõem a fazer a leitura?

Figura 1 - Apresentação gráfica sobre a leitura em sala de aula, segundo a visão do professor

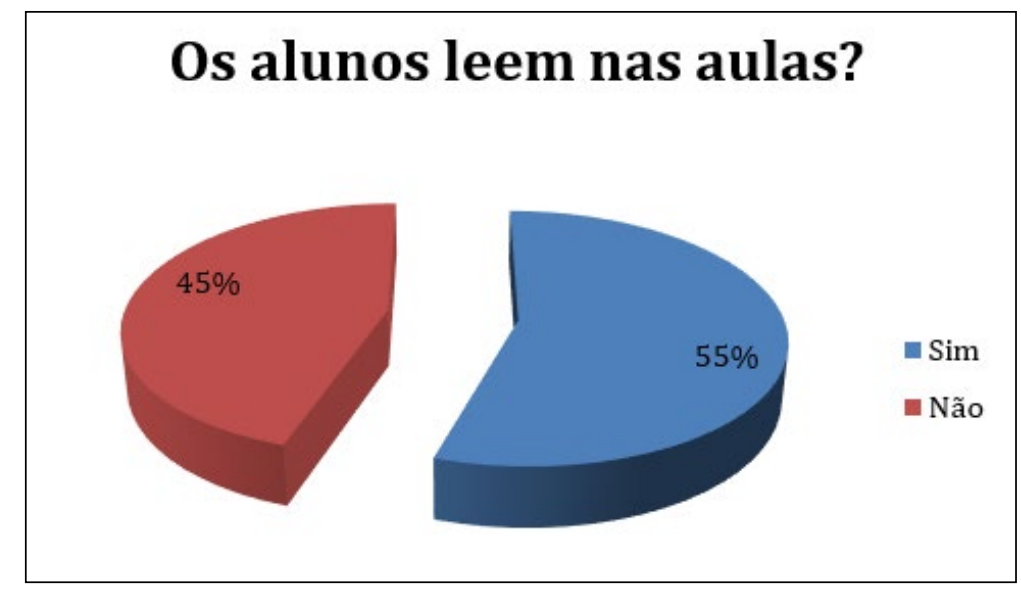

A Figura 2 traz o contraponto apresentando o resultado da pergunta feita aos alunos e os dados também surpreendem: os alunos gostam sim de ler! Aqui já podemos fazer uma pequena reflexão: se os alunos gostam de ler, por que, então, não leem nas aulas? Será que as situações de leitura não privilegiam a participação de todos? Será que são propostas situações de leitura? Será que os textos ou os materiais de leitura oferecidos na sala de aula são do interesse do aluno?

Figura 2 - Apresentação gráfica sobre o gosto pela leitura dos alunos.

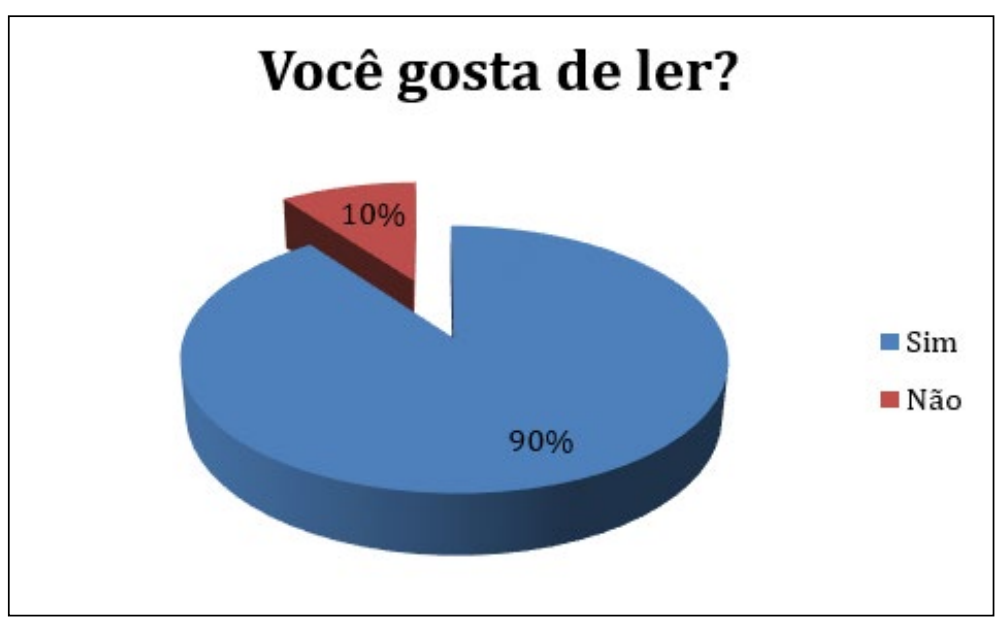

Para melhor problematizarmos a questão da leitura em sala de aula, perguntamos aos alunos se a leitura é exigida em todas as disciplinas, e os dados apontam que em algumas disciplinas a leitura não é sequer proposta. Trata-se de 
um dado que precisa ser bem analisado para evitar que conclusões precipitadas sejam tomadas e equivocadamente se apontem causas e consequências para este aparente problema. Como não identificamos a disciplina, não podemos dizer que esta ou aquela não cobra a leitura, como também a compreensão da questão pelo aluno sobre o que é cobrar leitura pode ser diferente da compreensão que nós professores temos. Os alunos, por exemplo, podem entender como cobrança de leitura apenas as exigidas como trabalho e que recebem uma nota dentro da média final do trimestre. Como dissemos antes, este dado serve para ensejar reflexão, ainda não é parâmetro para formular qualquer conclusão.

Figura 3 - Apresentação gráfica sobre a leitura em todas as disciplinas

\section{A leitura é cobrada em todas as disciplinas?}

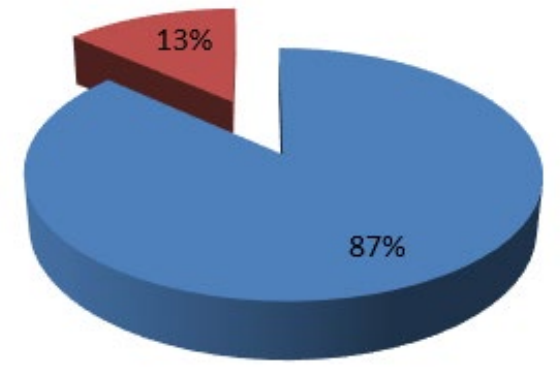

Sim

- Não

Continuando a análise dos dados, passamos à próxima questão feita aos professores. Desta vez, queríamos saber como eles planejam as situações de leitura em suas aulas. Os dados nos surpreenderam: a grande maioria dos professores não tem preocupação em planejar as situações de leitura. Uma porcentagem significativa adota como praxe seguir o livro didático; apenas $18 \%$ deles trazem temas atuais para debater em aula, alguns cobram leituras obrigatórias e um número menor ainda, destina uma hora semanal para a atividade de leitura. A análise desta questão, de certa forma, responde à primeira questão aqui analisada: os alunos não leem porque os professores não planejam situações de leitura em suas aulas.

Sobre o uso do livro didático, que foi uma resposta constante de parte dos professores, não queremos fazer crítica ao uso do livro didático em aula, apenas lembrar que ele é apenas um recurso e não o único meio de que o professor dispõe para dar a sua aula. Muitas vezes os temas abordados pelo livro não têm relação alguma com o contexto cultural, social e até econômico dos alunos. Chegar à sala de aula, abrir o mesmo livro todos os dias nas páginas indicadas pelo professor chega até a ser desestimulante. E, além disso, dois problemas sérios podem decorrer desta ação: 1) há professores que nunca leem para seus alunos - problema mais sério, e 2) há professores que preferem eles mesmos ler o conteúdo do livro para garantir 
que a leitura flua e que todos os alunos entendam o que está sendo lido, uma vez que dão a entonação devida, têm boa dicção e podem fazer interrupções, pausas na leitura, para fazer algum comentário ou chamar atenção para um devido dado. Enfim, esses professores não estimulam a leitura oral de parte dos alunos.

Por outro lado, alguns professores preferem que os alunos leiam, mas não direcionam o trabalho e deixam a 'leitura livre', ou seja, lê quem quer, e correm o risco de ter sempre os mesmos leitores. Ou ainda, aquele professor que pede para cada aluno ler até determinado ponto do texto para manter o silêncio na sala. Essa ação pode até garantir o silêncio, mas não é uma boa estratégia para assegurar que os alunos entendam o que leem ou que prestem atenção no que os colegas leem. É uma ação fragmentada que dificilmente resultará na compreensão global do texto lido. E para piorar, já que a situação não foi planejada, depois de feita a leitura, o professor pede que o aluno encontre respostas prontas, explícitas, no texto, não problematiza o conteúdo nem leva o aluno a refletir sobre o que o texto quer dizer nem a estabelecer relações com outras disciplinas ou com problemas reais que vivencia. Estas suposições, levantadas por nós a partir da comparação dos dados obtidos nas respostas de professores e alunos à questão proposta, são reais em muitas salas de aula. Aos poucos, então, começamos a delinear a gravidade do problema a ser enfrentado.

Figura 4 - Apresentação gráfica sobre como os professores planejam as situações de leitura

\section{Como você planeja as situações de leitura na sua disciplina?$$
\text { não planeja }
$$

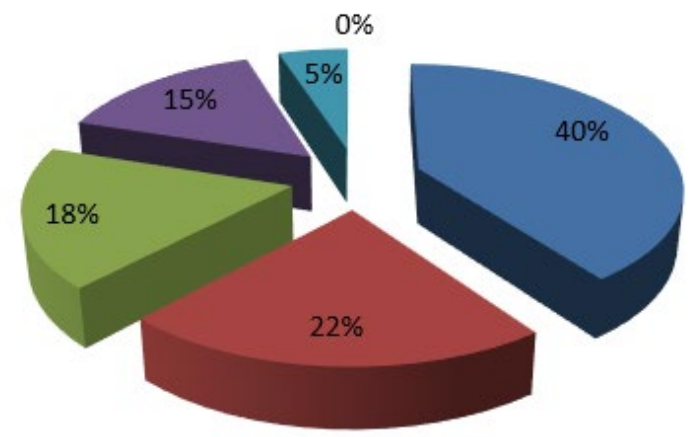

घegue o livro didático

v traz temas atuais para debater em aula

E cobra leituras obrigatórias determinadas pela escola

- destina uma hora semanal somente para leitura sem cobrar tarefas específicas

Para ilustrar as respostas fornecidas, a Figura 4 mostra o que resultou dos apontamentos sobre o problema de pesquisa. Apresentamos, na Figura 5, a seguir, os resultados da próxima questão feita aos alunos sobre a sua participação nas situações de leitura propostas pelo professor. Mais da metade deles disse que não participa; apenas um quarto respondeu que sim e quase a mesma proporção disse que participa raramente. Esses dados corroboram com o que discutíamos acima 
sobre o planejamento das situações de leitura e da participação dos estudantes nessas atividades.

Figura 5 - Apresentação gráfica sobre a participação dos alunos nas situações de leitura

\section{Você participa das situações de leitura propostas pelo professor no decorrer das aulas?}

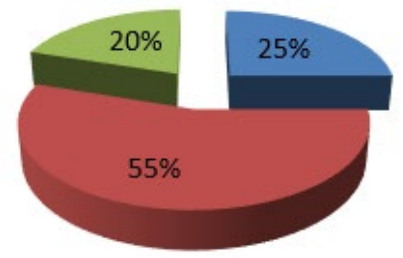

- Sim

ã̃o

- Raramente

Para problematizar ainda mais nossa pesquisa, perguntamos então aos alunos, se eles só leem na escola ou se têm o hábito de ler, se leem por prazer, e novamente os dados nos surpreenderam e complementaram os dados da Figura 2 que ilustra o gosto pela leitura: os alunos não só gostam de ler como também leem por prazer.

Figura 6 - Apresentação gráfica sobre leitura na escola e leitura espontânea

\section{Você só lê na escola ou lê espontaneamente, por prazer?}

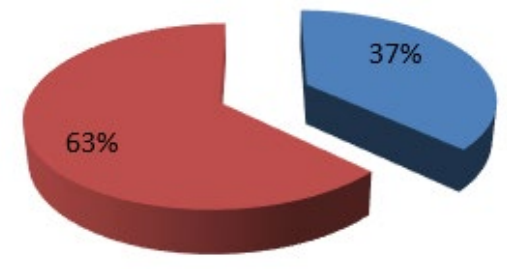

- Na escola

- Por prazer

Como vimos, o 'xis' da nossa questão não parece estar no aluno, mas no trabalho do professor, na forma como planeja suas aulas. Isso fica evidenciado na análise dos dados da próxima questão feita aos professores. Buscávamos saber qual o papel da leitura no desenvolvimento das suas aulas (tentando entender a Figura 5). Uma porcentagem pequena dos professores afirmou que a leitura não é relevante, que não depende dela para alcançar seus objetivos, mas para quase três quartos dos que responderam ao nosso questionário, a leitura é fundamental, uma 
vez que o desenvolvimento da aula gira em torno da leitura e compreensão do conteúdo. Os demais dados apresentados vão ao encontro das hipóteses por nós levantadas durante a análise dos dados fornecidos pelos professores: em geral, a leitura serve para manter o silêncio na sala; algum aluno que gosta de fazer leitura oral lê e o professor intervém quando necessário, não se preocupando se os demais alunos leem ou leram o texto; ou, então, o professor mesmo lê, não dando voz aos alunos evitando que façam intervenções que possam atrapalhar o andamento das aulas, tal como previsto por eles - professores.

Agora nos questionamos: se para a grande maioria dos professores, a leitura é fundamental, por que, então, os professores não propõem atividades de leitura partilhada? Por que não orientam a leitura a ser feita pelos alunos? Por que não possibilitam a todos os estudantes o desenvolvimento pleno da habilidade de leitura? Por que não buscam tornar os alunos hábeis leitores? Por que atribuir-lhes a "culpa" pelo insucesso na aprendizagem? Por que adotar um discurso em prol da leitura e desenvolver uma prática diferente da que pregam em seu discurso?

Até quando vamos continuar repetindo as mesmas práticas se sabemos que elas estão ultrapassadas, "capengas"? Temos que repensar nossa prática; parecenos que algo diferente precisa ser feito. Não estamos apontando soluções mágicas para o problema, apenas refletindo sobre o que fazemos, sobre a nossa prática real, despindo-nos da idealização.

Figura 7 - Apresentação gráfica da relevância da leitura para o desenvolvimento das aulas

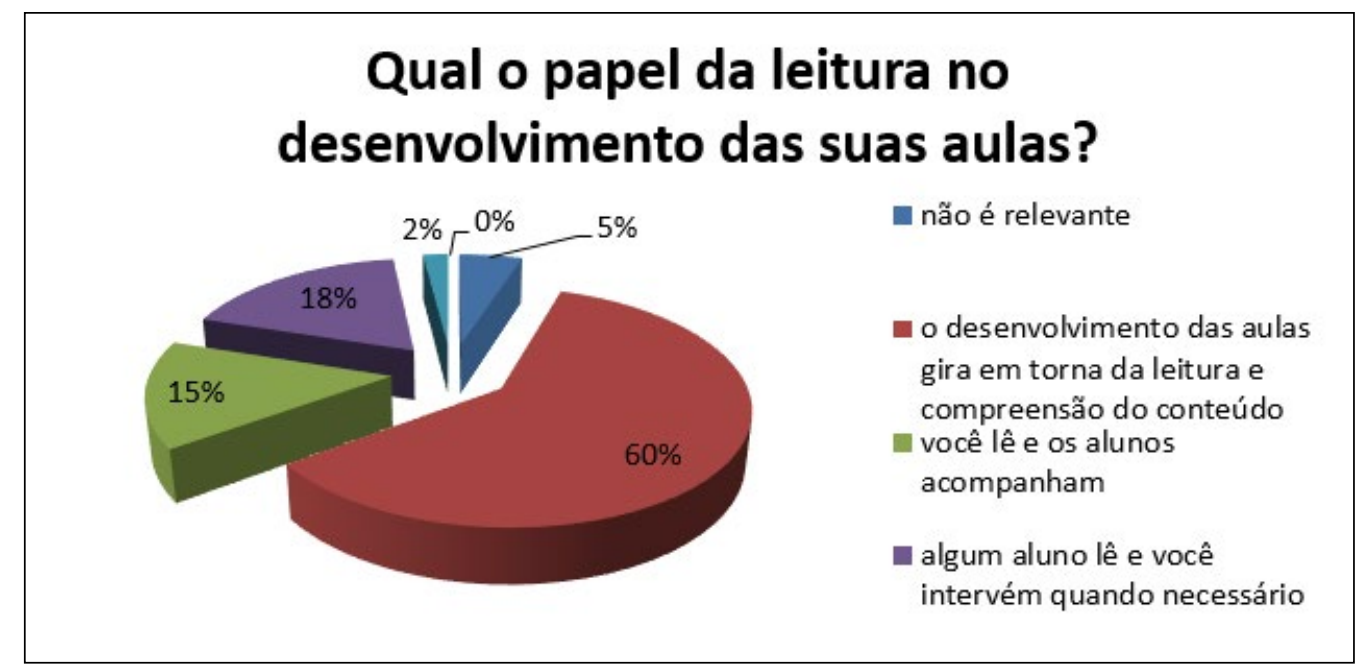

Os dados levantados até agora sinalizam que algumas atitudes precisam ser tomadas. E reforçamos essa afirmação através dos dados constantes na figura 8 que ilustra o conhecimento que os professores têm sobre a compreensão dos alunos em relação à leitura. Mais da metade dos professores afirma que seus alunos compreendem o que leem, mas nos preocupa o fato de que $37 \%$ deles dizem que os seus alunos não compreendem o que leem. 
Se a leitura e sua compreensão são fundamentais para o desenvolvimento das aulas, conforme vimos na Figura 7, a não compreensão por um número tão grande de alunos é preocupante. Como ficam esses alunos? Estão condenados à reprovação? Como fica o trabalho do professor? Faz de conta que não vê e aprova o aluno que não compreende o que lê, mesmo assim? O que têm feito os $37 \%$ dos professores que apontaram o problema para mudar essa realidade?

Mas o que mais preocupa, ainda, está por vir: há professores que admitem não saber avaliar se seu aluno compreende o que lê. Que atividades desenvolve esse professor que não consegue avaliar os alunos? Não realiza leitura? Lê só por ler? Os alunos não são instigados a refletir sobre o que leram? Deixamos em aberto esta questão para repensá-la mais adiante.

Figura 8 - Apresentação gráfica da percepção do professor sobre o nível de compreensão da leitura pelos seus alunos

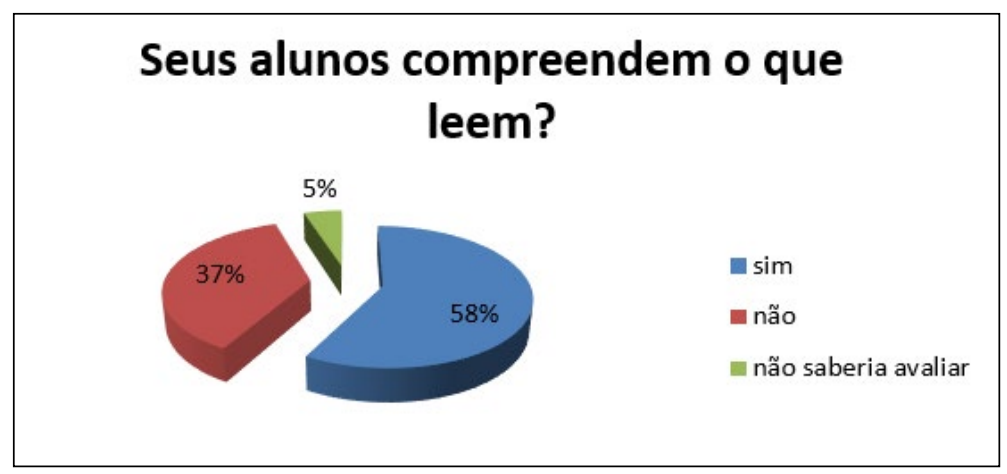

A última questão proposta aos professores buscava saber como avaliam a leitura nas suas aulas. Os dados apontam que $80 \%$ dos professores não avaliam a leitura nas suas aulas porque não é conteúdo da sua disciplina, 10\% fazem uma avaliação ao final do trimestre, exigindo a apresentação de um livro lido, e só 10\% avaliam constantemente, através das situações de aula. Esses dados indicam que a leitura é tratada pelos professores como conteúdo específico de uma disciplina e que não merece ou precisa ser trabalhada e exigida por professores das demais disciplinas. Outra vez temos dados apontando incoerência entre prática e discurso do professor, uma vez que afirmaram que a leitura é fundamental para o desenvolvimento de suas aulas e apreensão do conteúdo por parte do aluno. 
Figura 9 - Apresentação gráfica sobre como os professores avaliam a leitura

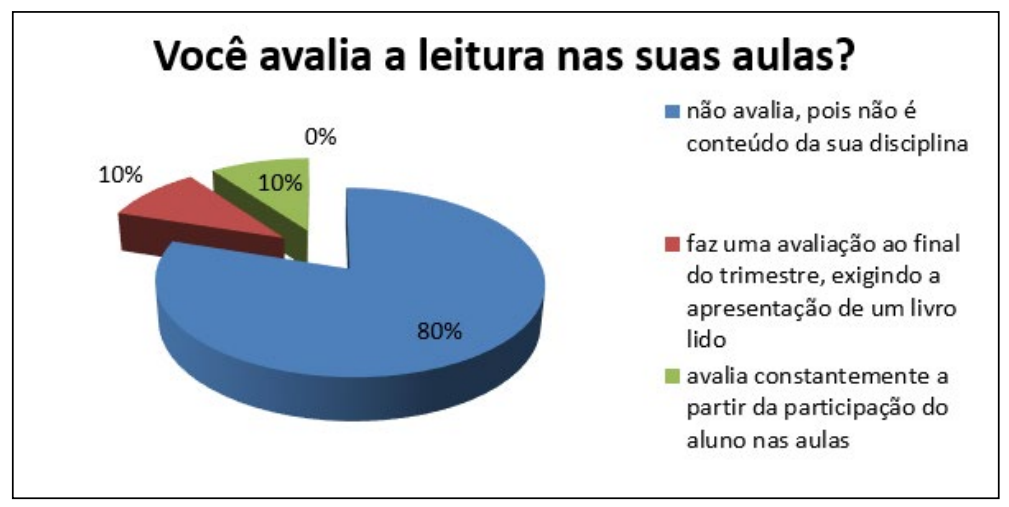

\section{Consideraçóes finais}

Diante dos dados que nos foram revelados, pudemos refletir sobre as situações que envolvem o contexto da prática de leitura em sala de aula. E com base nesses dados é possível dizer que parece haver um desencontro entre a fala do professor e sua prática, ou seja, é nítido um quadro de desvio do que seria o ensino de leitura. Destacamos mais uma vez que o nosso trabalho é apenas um recorte do trabalho desenvolvido nas salas de aula e não queremos generalizar, afirmando ser esta a realidade das salas de aulas. Mas é importante pensarmos nas razões pelas quais nossos alunos alcançam índices tão desastrosos nas avaliações de leitura.

Os dados coletados apontam que os professores não têm a preocupação de planejar situações de leitura, e aí está um grande equívoco: como qualquer outro conteúdo, a leitura precisa ser ensinada. O professor precisa ensinar o aluno a fazer inferências, a ler nas entrelinhas, a ser crítico. $O$ ensino da leitura não pode restringir-se apenas à decodificação num processo ascendente, com o significado centrado no texto. $\mathrm{O}$ aluno precisa sair da condição de espectador passivo, de memorizador de conteúdos.

Para Lajolo (1982, p.59), "ler não é decifrar, como num jogo de adivinhações, o sentido de um texto". Ao contrário, a partir do texto, ler é atribuir significado, é relacionar informações, é reconhecer o tipo de leitura que o autor pretende, é também rebelar-se e propor outra leitura não prevista. Para a autora, as práticas docentes estão muito defasadas e não priorizam o ensino e a promoção da leitura. As atividades com leitura, geralmente, são descontextualizadas e fragmentadas, não fazendo sentido para o aluno. Em muitas situações de aula, servem para orientar o roteiro da aula, ou seja, a leitura de um texto serve para o aluno responder a um questionário ou seguir uma sequência do livro didático.

Outro dado muito relevante da nossa pesquisa vem das respostas dos alunos: eles gostam de ler. Então aquele nosso velho discurso de dizer que nossos alunos não leem parece não ser verdadeiro. Eles leem mais fora da escola do que na escola e não leem por obrigação, mas por prazer. Por que então não nos valermos desta 
situação favorável que nos assegura que não precisamos despertar o gosto pela leitura, pois ele já existe? O que temos que fazer é ensinar a ler; precisamos ler em sala de aula, mas não uma leitura decodificada, e sim uma leitura que tenha sentido, que desperte a criticidade, a imaginação, a criatividade. Uma leitura que vai além do código escrito. Uma leitura significativa que leve à compreensão. Este é o desafio da escola: ensinar o aluno a ler e compreender.

E para concluir, repetimos uma fala que já usamos anteriormente: - o problema da leitura, ao que nos parece, não está no aluno, mas na prática docente, no trabalho que é realizado em sala de aula. É muito mais cômodo atribuir ao aluno a responsabilidade pelo insucesso na aprendizagem do que reconhecer nosso fracasso enquanto professores de qualquer que seja a disciplina curricular. Se a leitura é um dos meios pelos quais as aprendizagens acontecem em todas as disciplinas, o seu ensino precisa ser planejado e avaliado em todas elas. Porque, afinal de contas, como diz Flores (2008, p.11), "a leitura é uma questão política da maior relevância"; a escola precisa preparar o estudante para ser alguém além de repetidor daquilo que está no texto, precisa prepará-lo para assimilar, pensar, sistematizar e dar sentido às ideias trazidas pelo texto.

\section{Referências}

ASSOCIAÇÃO BRASILEIRA DE NORMAS TÉCNICAS. Informação e documentação. Artigo em publicação periódica científica impressa - Apresentação. NBR 6022. Rio de Janeiro, 2003.

FLORES, O. C; PEREIRA, V. O grau dez da leitura: lendo como escritor - escrevendo como leitor. Porto Alegre: WS Editor, 2000.

FLORES, O. C. Linhas e entrelinhas: leitura na sala de aula. Santa Cruz do Sul: Edunisc, 2008.

LAJOLO, M. O texto não é pretexto. In: AGUIAR, V. T.; ZILBERMAN, R. (orgs).

Leitura em crise na escola: as alternativas do professor. Porto Alegre: Mercado Aberto, 1982. p.51-62.

LERNER, D. Ler e escrever na escola: o real, o possível e o necessário. Porto Alegre: Artmed. 2002

MORAIS, J. Criar leitores: para professores e educadores. São Paulo: Minha Editora, 2013.

PISA-Inep. PISA. Disponível em: < http://portal.inep.gov.br/pisa-programainternacional-de-avaliacao-de-alunos>. Acesso em: 02 maio 2014.

PISA. Desempenho do Brasil piora em leitura e “empaca” em Ciências. Disponível em: <http://educacao.uol.com.br/noticias/2013/12/03/pisa-desempenho-do-brasilpiora-em-leitura-e-empaca-em-ciencias.htm>. Acesso em: 02 maio 2014.

SOLÉ, I. Estratégias de Leitura. Porto Alegre: Artmed, 1998. 